\title{
Lhis TEXT
}

Australasian Association of Writing

Programs
Journal of writing and writing courses

ISSN: 1327-9556 | https://textjournal.scholasticahq.com/

TEXT Volume 24 No 2 October 2020

\section{Editorial}

\section{The employability of the creative writing PhD}

Once upon a time, no one worried over the employability of arts and humanities doctorates. Your $\mathrm{PhD}$ in English, History, Philosophy, etc likely guaranteed you an academic job in a major, or less well known, tertiary institution. If you didn't become permanently employed, it meant you were weird (as some of us arts and humanities graduates are). So, while personality might sway the selection panel in terms of suitability to join an existing team, the qualification was rarely disputed. Back then, a small pool of eminently qualified applicants vied for each job. Those days are gone.

People with PhDs now drive Ubers, wrangle espresso machines, and suffer tertiary education's exploitation of its casualised work force.

I don't claim expertise in understanding the trials and tribulations of emerging academics, but I sincerely worry about the sense of gloom that pervades their thinking. And it seems to me the major influence on that thinking, that gloom, was imposed by the older generation (to which I belong) in its limited understanding that the only usefulness of a $\mathrm{PhD}$ was as a ticket to work in a university.

I am aware of exceptions. The following are recent creative writing $\mathrm{PhD}$ graduates who thought not to rely on the university sector to give them a job. Notably, they looked elsewhere early on in their postgraduate study years - sometimes out of necessity, sometimes with a plan in mind.

Case study A: Student A applied for a job as a publisher's rep immediately after gaining Honours in creative writing. She was successful and consequently did her $\mathrm{PhD}$ part-time. She wanted to write novels for teenagers, but felt she should get a 
proper job as well. She stayed as a rep throughout her $\mathrm{PhD}$ years, working with the publisher's non-fiction list. This was not her favourite area of writing, but she stuck at it. When she finished her creative $\mathrm{PhD}$, Dr A left publishing and got a job with a state government department in an information-writing area. Last we heard, she was promoted to head of a significant sub-department in an area which has nothing to do with books, but where plenty of writing goes on to inform the public about government policy, laws and regulations. Dr A can now write novels for teenagers if she wants to.

Case study B: During her creative writing PhD studies, Student B's husband had a disabling accident so she needed to find a part-time job to keep the household going. A chain of retirement homes advertised for someone to run storytelling and storywriting courses in their facilities across the region. Student B applied, and got the job. She was so successful at it, the retirement company offered her a full-time job once she finished her studies. Last we heard, Dr B had developed the program to fuller and broader applications. Her $\mathrm{PhD}$, which produced a creative biography of a poet who died during the candidature, turned out to be an ideal preparation for the career she took on.

Case study C: Student C's jobs to support himself during his creative writing Masters and $\mathrm{PhD}$ included serving in bottle shops, working as an all-night parking attendant (where he wrote drafts in poorly-illuminated carpark booths) and driving a truck for a construction company. Unlike students $\mathrm{A}$ and B, Student $\mathrm{C}$ seriously wanted to be a creative writing academic. After becoming $\mathrm{Dr} \mathrm{C}$, he worked as part-time tutor and lecturer while still driving trucks and having a crack at Uber driving ('Not good', he says). Dr C finally gave up on academia and applied to be a truck-driving instructor. He got the job and found his university experience provided compatible prior learning credit for the teaching certificate he needed. Last we heard, while universities decimated casual staffs during Covid, Dr C has good hours teaching aspirant truckies how to change gears. He can continue to write novels in his spare time, if he wishes.

There are sad and good things about each of these case studies. Universities in recent decades have situated the $\mathrm{PhD}$ as a 'research training award' - currently seen as something not useful unless you intend to practice in a university or other research context - but this notion is out of date.

The $\mathrm{PhD}$ is a highly significant enhancement to one's employability, even in tough economic times, and it has outstanding usefulness to society. $\mathrm{PhD}$ graduates can contribute with wide application to a nation where undergraduate degrees are dumbed down and where education policy is on a constant trajectory of reduced budgets. 
The enhanced knowledge gained during a $\mathrm{PhD}$ can be immediately applied in a vocational context, as opposed to being saved up for use in the knowledge log-jam of a research institution. Business and government who employ PhDs get the instant benefit of highpowered agents for change. Current tertiary education produces mainly smart people. It needs to produce many more super-smart people.

But our PhD students need to play the game right where philistine governments don't understand that the arts and humanities provide the context in which society's decisions are made. I've read a lot of neuroscience and cognitive psychology research lately, and it's surprising to see how many science papers begin by referencing literature, history and philosophy. It's almost a cliché of science writing: in the introduction the experimenter lays the groundwork by quoting well-known human beliefs and issues as already convincingly documented by philosophers, poets, and fiction writers.

Neuroscientist Joseph E LeDoux calls science and the humanities 'complementary endeavours' in solving the 'hard problems' of living (LeDoux 2018: x). He says: 'Scientists are not necessarily in the best position to figure out what those big questions [of existence] are. Fortunately, this is just what the humanities are all about' (xii).

Creative writing PhDs are potentially gold, providing that the awardee does not insist they want employment in a university. PhDs carry the weight of study at the highest level acknowledged by the tertiary education sector. The above case studies suggest you have to think about your career seriously at the Honours level, and make choices from that point forward. The current climate involves you thinking like an archer. You don't survive with just one, or even two, strings to your bow. Go for multiple strings to fire into the future.

\section{-Nigel Krauth}

Scholarly contributions to the October 2020 edition of TEXT canvas a range of research problems, from doctoral pedagogy to the role of the imagination in the creation of sensory narrative detail, from critical approaches to worldbuilding to the problem of the anti-heroine. Contributing authors also engage a wide range of forms including scriptwriting, prose poetry, realist fiction, sci-fi and fantasy and experimental life writing.

In "Writing Together: Conjunctive collaboration, scholarship and prose poetry" Cassandra Atherton (Deakin University) and Paul Hetherington (University of Canberra) find a paucity of models for co-authorship or collaboration in the field of academic scholarship in the humanities. Their article seeks to address this gap by reflecting explicitly on their recent collaborative work as creative writing academics, outlining both the challenges and the opportunities afforded by working together on scholarly publications. 
Elsewhere, Cassandra Atherton collaborates with fellow prose poet Alyson Miller (Deakin University) in order to discuss the complex space occupied by Chernobyl in the Western cultural imagination and to argue against the idea that tragedy is 'unspeakable'. Their article explores poetry that attempts the difficult task of writing about the horrors of nuclear disaster in order that such events are not silenced and forgotten.

Researchers from RMIT University contribute two related articles to this edition, one coauthored by Michelle Aung Thin et al and the other sole-authored by Francesca Rendle-Short. The first presents a case study of $\mathrm{PhD}$ pedagogy underway through RMIT with writers from across the Asia-Pacific and known as the Practice Research Symposium or PRS. The article invites readers to reconsider how a $P h D$ by practice in creative writing contributes new knowledge: it is a fitting follow-up to the articles on $\mathrm{PhD}$ pedagogy by West and Magee published in our April 2020 edition. Aung Thin et al offer a more publicly-oriented and cohort-based model of a doctoral program compared to other recent case studies discussed in TEXT: their work reflects the depth of thinking going on in Australia now around practice as research.

Relatedly, Rendle-Short's article builds on and extends ideas of practice she has encountered as a doctoral supervisor in the PRS model, where the primary focus of practice-led research is 'to advance knowledge about practice, or to advance knowledge within practice' (Candy and Edmonds 2018). Rendle-Short's article maps a series of iterative creative works that she has created and/or made over a long period, investigating, in particular, the value in thinking prepositionally and with/through the syntax or grammar of creativity. It is a valuable contribution.

Julia Prendergast (Swinburne University) extends her previous work on dark subject matter in the genre of dirty realism by contemplating the relationship between sensory narrative detail and the focalising consciousness. Her article is an argument for a sustained and rich relationship between reading and writing, reflecting on the work of Helen Garner, Raymond Carver and Josephine Rowe, among others, with a special emphasis on the way the focalising consciousness "captures tactile events through a concrete and specific lens, in minutiae" in order to transform the text into "a tangible assemblage of the otherwise unsayable."

In "A Flare of Light or The Great Clomping Foot of Nerdism? M. John Harrison's radical poetics of worldbuilding" Helen Marshall (University of Queensland) acknowledges the centrality of worldbuilding to the art of science fiction and fantasy writing, but provides us with a welcome counterpoint. Tracing the critical and creative contributions of M. John Harrison, Marshall evaluates Harrison's 'poetics of scepticism toward worldbuilding' and finds it valuable. Marshall finds a contrast between the approach of Harrsion and that taken by more contemporary worldbuilders including China Miéville, Jeff VanderMeer and Timothy Morton. 
Finally, we're excited to introduce $T E X T$ readers to two early career researchers publishing in TEXT for the first time.

Levi Dean (Bangor University) explores the challenges of scripting an anti-heroine teleplay in the long shadows cast by the work of Christopher Vogler and Joseph Campbell. His article sets out to define the archetypal features of a television anti-heroine to aid screenwriters with scripting in this genre, while acknowledging the challenges of gender bias in traditional approaches to writing screen heroes.

And independent scholar Abigail Fisher takes up the notion of an embodied erotics of translation in response to the work of Aarón Lacayo and Luce Irigaray. We're especially pleased to be publishing Fisher's accompanying creative work in the poetry section of this edition and we encourage TEXT readers to consider reading across and between these two distinct but interrelated research outputs.

—Julienne van Loon and Ross Watkins

With this issue of TEXT we see the departure of Amelia Walker and Pablo Muslera as Reviews Editors. Over the last three years they have done an outstanding job and we thank them unreservedly for their contributions. Amelia has also helped, in her sterling way, with the reviews section for this edition.

We now welcome Dom Symes as Reviews Editor. He has seen the current set of reviews through to publication, and we know Simon-Peter Telford, who assisted Amelia and Pablo in recent years, will continue his excellent support.

The reviews section of TEXT provides a lively arena for recognition of newly-published works in the creative writing field relevant to AAWP readers.

- The Editors

\section{Work cited}

LeDoux, JE 2018 'Foreword', in J Tougaw, The Elusive Brain: Literary experiments in the age of neuroscience, Yale University Press, New Haven: ix-xii 